\title{
Building the People-to-people Bond in the Belt and Road Initiative: A Case Study of Digital Visual Communication
}

\author{
Ming Guo \\ Macao University of Science and Technology, 999078, Macau \\ Guangdong Polytechnic of Science and Technology, Zhuhai, 519000, China \\ guodream@163.com
}

\begin{abstract}
People-to-people bonds are placed as a crucial part in the core of "One-Belt \& One-Road". Featuring big data and mobile internet, New Media will play a role affecting international opinion, as well as interaction between China and the world. Efficiently availing creative international propagation with visualized content can profoundly boost China's among countries involved, then spur output of cultural values and communications with locals, and thus build people-to-people bonds. In this visualized digital era, intercultural communications among various groups on multiple platforms are beneficial to self-recognition of cultural identities; deep integration of audio-visual and digitalization will improve the capabilities and efficiency of international propagation, largely enforcing centripetal force of people-to-people bonds. The following are strategies I suggest for building people-to-people bonds: 1) To build a mode based on connected clouds and an intelligent interconnected propagation system; 2) To construct a mechanism as well as canals to propagate cultural industries; 3 ) To place great importance on innovation of cultural products and new media in order to meet the demands of international markets.
\end{abstract}

Keywords-International Communication; People-to-people bond; Digital Visual Communication

\section{INTRODUCTION}

The "One-Belt and One-Road" is a new model of international regional economic cooperation put forward by China to promote the in-depth development of economic globalization [1]. It is the process of re-globalization of Chinese culture and international communication, Marking the Chinese culture, "going out" the era of globalization is the spread of distinctive features. With the arrival of the new media era in the world and the continuous expansion of the breadth and depth of diverse cultural participation in neighboring countries along the Belt and Road, To tell the story of China, to interpret the unique Chinese characteristics, demonstrate the unique charm of Chinese culture, enhance the international voice, and comprehensively enhance the national cultural soft power, we need to innovate and disseminate ways and means under the new concept of new technology and effectively disseminate the values of contemporary China, build the people-to people bond and Promote communication and understanding.

\section{NeCESSITY OF BUILDING THE PEOPLE-TO-PEOPLE BOND}

The people-to-people bond is still a relatively new issue, Based on the data from Zhai Kun's paper "A study of the 21st Century Maritime Silk Road in the Perspective of the peopleto-people bond index between China and ASEAN", "The development of common people's feelings can be divided into 'smooth' (8 points and above), 'good' (6 to 8), 'potential' (3 to 6) and 'weak' (3 points or less). Singapore, Thailand, Malaysia and Indonesia all had a standardized score of at least 8 points, which was a "smooth" type of country. In Cambodia and Laos, the standardized total scores were 6.95 and 6.53 respectively, which belonged to the "good" countries. Vietnam, Myanmar, The Philippines and Brunei total score less than 6 points, belong to the 'potential' countries. However, the standardized scores of China are all above 4.8 points [2]. Although the overall situation is good, the potential of people's mutual understanding is still huge. There is still a gap with the reality.

First, China's status as an economic powerhouse is very attractive to countries along the "Belt and Road". China is already the second largest economy in the world with GDP of over 10 trillion dollars and its foreign investment exceeds 100 billion dollars every year. It is the largest trading partner in over 120 countries. In 2015, China contributed over $25 \%$ of global economic growth [3]. Chinese enterprises directly invest in 49 countries related to the "Belt and Road Initiative and the investment reached 14.82 billion dollars, an increase of $18.2 \%$ [4]. The economic relations between the existing investment and construction projects in the countries along the line and the investment sides of the existing China closely form the basis for the people-to-people bond.

Second, under the Western discourse system, negative comments such as "China threat theory" and "China's rule of hegemony" are emerging in the final analysis is a result of asymmetry information. Without the effective communication of the idea of The Tianxia system in Chinese traditional culture, other people in the world can not understand China's theory of non-hegemony, and the people-to people bond is the purpose and result of resolving this issue. The principle of loyalty and forgiveness in the Chinese traditional culture and the thinking of Tianxia system are a good illustration of the cooperation mode of not seeking hegemony, exploitation, cooperation, 
mutual benefit and win-win situation in the construction of China's "One Belt and One Road". Therefore, the people-topeople bond is an appropriate practice of the international contacts influenced by Chinese traditional culture.

\section{DIGITAL VISUAL COMMUNICATION ON THE ROLE OF BUILDING THE PEOPLE-TO-PEOPLE BOND IN THE BELT AND ROAD INITIATIVE}

"The interaction between the state and the state lies in the mutual trust between the people” (“国之交在于民相亲, 民相 亲在于心相通”). In the final analysis, the relations among nations are human-to-human relations. Only by moving people's hearts can deep cooperation in all fields be realized [5] In this visualized digital era, intercultural communications among various groups on multiple platforms are beneficial to self-recognition of cultural identities; deep integration of audiovisual and digitalization will improve the capabilities and efficiency of international propagation, largely enforcing centripetal force of people-to-people bonds.

First, creating a good national image is beneficial to selfrecognition of cultural identities. McLuhan referred to the "identity" deprivation of electronic media, when people interact with each other directly by means of electronic media; it is the direct involvement of the central nervous system to form each other's deep involvement. The ancient Silk Road in history is not only a business road, but also a platform for people-topeople and cultural exchanges. The Chinese culture of the Benevolent spirit, People-based thought, The Greater good and Self-interest mentioned by president Xi Jinping, it emphasized that the "One Belt and One Road" interconnection and exchange is different from the cultural imperialism, cultural colonialism and cultural hegemony formed in the globalization of Western civilization in the past. It is an action to encourage local governments and people with different values to share in the process of creating results along the way. And it is also a cultural contact, cultural participation and cultural exchange for a better life and sustainable development. Nowadays, the new ideas, new initiatives and new visions of the international communications and international order such as the "One Belt and One Road," interconnection and connectivity, and the community with a shared future in cyberspace are in line with the starting point for exploring international communications on the mobile terminal in the world today. Big data, cloud computing, sensing technology, intelligent things is the basis to achieve the future of smart media technology. The subversive promotion of the ability to disseminate information through the smart Internet will bring about the world's sensory, cognitive and service systems. The supply of media will be highly matched to the needs of users, and the boundaries of the power of traditional communication will become increasingly blurred. The media will be everywhere and the world will be reconnects [6].

Second, make a good story of China can raise the concentric of the people-to-people bond. An important part of the people-to-people bond is to tell a good story of China and tell a good story about China's Belt and Road initiative. 1) Digital visual communication can reduce cognitive load. In the study of cognitive theory, John Sweller proposed cognitive load theory, He believes it exists three kinds of cognitive load that from the different sources: One is intrinsic cognitive load, It is caused by the structure and complexity of learning materials; Another is extraneous cognitive load, It is caused by the form and manner in which information is presented. The third is germane cognitive load; it is made by the learner hard working to understand material [7]. 2) Digital visual communication fits the way of the audience using the media. The way and motivation of the audience to use the media is an important indicator of the media's infiltration and influence. The mobile terminal is an important battlefield. The media ecosystem is undergoing profound changes with the three major "media" such as mobile terminals, smart hardware and live broadcast applications. People in the text, pictures of expression in the PC era have been fully satisfied in the past, Nowadays, mobile terminals and mobile video broadcast greatly satisfy the people's requirements for timeliness and interactivity of content. Accurate dissemination in the smart media era is the most effective way of communication, during the "One Belt and One Road" international communication process, the more we can formulate targeted communication strategies which based on different groups of people, the better the accuracy and persuasion of communication. In particular, according to the audience the habit of accepting information, the same content can be made different versions of production to communicate better. 3) The innovation of Media language is conducive to accurate dissemination. Over 60 countries along the Belt and Road use different languages. Regardless of the diplomatic department or business, workers, skilled personnel in the local language are very small. "Another example is the Central Asian countries, South Asian countries, Southeast Asian countries, 29 countries use nearly 1,000 languages dialect, the official language and Mandarin about 60 species, few universities offer these language majors, and enrollment is small, And 18 languages do not have a professional. [8]" Language communication is the basis of the people-to-people bond.

\section{THE WAY OF DIGITAL VISUAL COMMUNICATION} Promoting THE PEOPLE-TO-PEOPLE BOND IN THE BELT AND ROAD INITIATIVE

At present, we often fall into passive scolding situations in the international public opinion. The strength of China's international media, whether it is spread or influential, is relatively weak. Only by enhancing the capabilities of international communication, effectively improving China's international public opinion environment and effectively sending out the voice of China and only then it will be recognized and understood by the governments and people in other countries.

(1) To build a mode based on connected clouds and an intelligent interconnected propagation system; "The Internet is more than just a medium. What is more essential is that it is a structural force that reconstructs the world. This is its real meaning [9]." To build the people-to-people bond, It not only needs to build an international platform to connect China with the world, it also needs to build a platform to let the world better understand China. This will require the integration and 
co-ordination of all channels and technologies for the promotion of international communication capacity.

President Xi already put forward two great initiatives such as the "Silk Road Economic Belt" and the "21st Century Maritime Silk Road" in 2013. New media on the Weibo, WeChat, client and other platforms, issued a "Belt and Road" coverage, measured in million units. Xinhua News Agency, China, was reported by more than 10 countries and regions 343 Chinese media reprinted, China Radio International is Focusing on Key Coverage of Six Strategic Regions in the World. From a quantitative point of view, relevant reports of the "Belt and Road" already have the effect of "growing up", but this is only a kind of "landing" and is not necessarily related to "getting into the heart [10]." Using digital visualization to disseminate the powerful information integration capabilities in the mobile Internet, and build an intelligent international communication System. Intelligent media with digitalization and interaction as its core features will form a powerful information integration capability on the mobile terminal, which not only increases the channels of information dissemination and the speed of information dissemination, but also opens up the space-time separation between people and people. Form a "universal network" of intelligent interoperability. The big data 7V features: Volume, Velocity, Vast, Variety, Value, Veracity, Visualize [11]. Will help people better collect and organize the massive information to achieve the seamless transmission of globalization push mode. Convey the obscure concepts, information and knowledge to ordinary people along the "Belt and Road" through data maps, digital presentations and interaction. With a more vivid illustrations, audio-visual ways to speak a good Chinese story, to achieve the purpose of Information dissemination, Internalization of ideas and Attitude evolution.

(2) To construct a mechanism as well as canals to propagate a digital cultural industry, innovative digital cultural industry communication channel, promote excellent multi-channel transmission of literature and art, multi-platform display, multiterminal push. The key to building a digital cultural industry transmission mechanism is to uphold new media thinking, media spirits, and creative change media language; In the process of "content integration", innovate the production and presentation of content and enhance the stickiness of content; In the process of "technology integration", pay attention to the use of technology, the development of terminal platform and the cultivation of qualified personnel; Eventually achieve the modernization of cultural transmission system, the threedimensional shape and diversification of channels.

Network big data era, a profound change in the path of communication has taken place. The forms of communication are becoming more diverse through $\mathrm{Html} 5$, interactive design, animation, 3D, virtual reality and more. Content is published in a variety of applications such as WeChat, Weibo, APP client, social platform. A variety of terminals such as mobile phones, TVs, tablets, watches, cars, VR, etc. will also be integrated with the Internet to change the audience's multi-screen reception experience. Digital television networks, satellite networks, the Internet, IPTV and other networks will adopt the "data + scene + story" approach, equipped with cloud platform and intelligent operating system to achieve the spread of content from read to visual, from static to dynamic, from Onedimensional to multi-dimensional data presentation; In the future, we will create data and information products, solutions and localized service delivery channels suitable for users' needs integrate various resources and continuously enhance their service capabilities so as to help governments and enterprises enhance the ability of cultural transmission in smart media environments.

(3) To place great importance on innovation of cultural products and new media in order to meet the demands of international markets.

Cultural Industry Development Plan of Ministry of Culture during the Thirteenth Five Year Plan specifically defined: With digital technology and advanced concepts to promote cultural and creative design and innovation and other industrial development, promote deep integration of culture and science and technology. By 2020, a pattern of digital creative industries with leading culture, advanced technology and complete chains will be formed [12]. We will vigorously develop the international cultural and media industries, thoroughly tap the rich cultural resources of the countries and regions along the "Belt and Road", including the unique cultural resources of the two rivers basin civilization, Christian civilization, Greek civilization, Indian civilization and Chinese civilization. According to the characteristics of cultural resources in different countries, based on the strategic identity of cultural consensus, we should establish a platform for the cooperation and development of cultural industries in different values and a competitive cultural format, and promote interpersonal contacts and cultural exchanges among regions. In particular, focus on the development of cultural industries that give priority to the development of film, media, digital books and animation industries and integrate a group of emerging media industry companies engaged in businesses such as Internet TV, mobile $\mathrm{TV}$, online video and mobile Internet, Media Group, with its own dissemination of advantages and planning capabilities, together with the Internet and related cultural industries, It is an effective way to carry out industrial transformation in light of its own characteristics. This is a very important breakthrough for the expansion of China's cultural industry that Starting from the effect of visual communication, the digitization of cultural products has made innovations in the transmission mode of traditional Chinese culture and achieved interconnection and interoperability. 


\section{CONCLUSION}

Driven by science and technology, the speed of media evolution will be faster and faster, Media tycoon Murdoch once said: Technology is shifting the prerogative of communication among editors, publishers, authorities and media elites, and it is now the age at which the people are in charge of communication [13]. The spread of digital visualization, digital visual culture and creative symbol system has become an irresistible trend in Building the People-to-people Bond. This is not only the requirements of the times but also the inherent requirement of going out of Chinese culture, which is not only related to the needs of the people but also to the development of the nation-state. With the continuous rise of China's national economic strength, China's international communications will also provide excellent technological innovation, an active media industry and a wealth of dissemination practices to build a deep-seated and multi-dimensional cultural opening-up for the Belt and Road construction along the way, Promote Chinese culture to the world.

\section{REFERENCES}

[1] Gao li. Analysis of the Ways to Realize the Belt and Road Initiative under the Economic Globalization, Global market,2016(6) pp.4.

[2] ZHAI Kun, A Study of the 21st Century Maritime Silk Road in the perspective of the people-to-people bong index between China and ASEAN. Journal of Yunan Normal University (Philosophy and Social Science Edition), 2016, Vol. 48, No. 6, p. 55.

[3] Wang Baoan, director of the National Bureau of Statistics, answered in a press briefing on the national economic operation in 2015 [EB], January 19, 2016. Chinese government network.

[4] China is still the "power source" of the world economy [N], People's Daily, January 28, 201601 version.

[5] Xing Liju.The Humanistic Exchanges Beneficial to the "Belt and Road Initiative": Difficulties and Their Possible Solutions. International Issues Research. No.6.2016.

[6] "Mass Media Times - The New World Order of Text, Images and Sounds".Tencent Media Research Institute. CITIC Publishing House. March.2016.

[7] Ding Daqun, LuoYangmei, The Effect of Cognitive Style andINformation's Presentation Format on Cognitive Load. New Psychology, 2009 (3) vol. 29 p. 37.

[8] Wang Xiang Sui "Belt and Road can not do without the communication with local people" Literature review. Economic Guide. 2017(2).PP.29.

[9] Yu guo ming . Internet is a "high-dimensional" medium, and "platformbased media" is the mainstream mode of future media development,"News and Writing". 2015(2).PP.41-44.

[10] Zhou Jun . Innovate "One Belt and One Road" Strategy with Big Data. Media observation 2015 (07).

[11] Xu zhiqiang. Research on the Mode of Innovation and Development of Intelligent Media. Theoretical exploration. 2016(6) No. 12.

[12] "Ministry of Culture," 13th Five-Year Plan for the Development of Culture Industry "to Promote the Flourishing Development of Digital Creative Industries and Create New Leading Consumption.

[13] Yu xia,Cao na. Full Media and "Breaking the Era" - Reflections on Advertising Communication in the All Media. China published.2013(6). PP28-31. 